\title{
Use of dexmedetomidine for pain control
} Irina Grosu and Patricia Lavand'homme*

\author{
Address: Department of Anesthesiology, Saint-Luc Hospital Medical School, Université Catholique de Louvain, Avenue Hippocrate 10-1821, \\ B-1200 Brussels, Belgium \\ * Corresponding author: Patricia Lavand'homme (patricia.lavandhomme@uclouvain.be) \\ Fl000 Medicine Reports 2010, 2:90 (doi:10.3410/M2-90) \\ This is an open-access article distributed under the terms of the Creative Commons Attribution-Non Commercial License \\ (http://creativecommons.org/licenses/by-nc/3.0/legalcode), which permits unrestricted use, distribution, and reproduction in any medium, \\ provided the original work is properly cited. You may not use this work for commercial purposes. \\ The electronic version of this article is the complete one and can be found at: http://f1000.com/reports/m/2/90
}

\begin{abstract}
For many years, clonidine, an $\alpha 2$-adrenergic receptor $(\alpha 2-A R)$ agonist, has been widely used as an analgesic adjuvant in perioperative conditions and pain therapy. Dexmedetomidine (DMET) is currently the most potent $\alpha 2-A R$ agonist available and was first approved as a sedative agent for use in the intensive care unit. However, DMET has recently been investigated for its analgesic effects and has the potential to become an alternative to clonidine.
\end{abstract}

\section{Introduction and context}

Clonidine, an $\alpha 2$-adrenergic receptor $(\alpha 2-\mathrm{AR})$ agonist, has been widely used and investigated as an analgesic adjuvant for anesthesia and pain therapy. Dexmedetomidine (DMET) belongs to the same family but presents with a different, more favorable pharmacokinetic profile (Table 1). DMET was first introduced into clinical practice as a short-term intravenous sedative in the intensive care unit. Because the drug also demonstrates analgesic properties related to $\alpha 2$-AR binding (DMET is 8-10-fold more selective for $\alpha 2$-AR than clonidine), several studies have investigated its use as a systemic analgesic adjuvant, mostly in the acute perioperative setting [1]. More recently, DMET has been investigated as an adjunct to local anesthetics in locoregional anesthesia and analgesia. However, neurotoxicity studies have not yet been performed [2] and the benefit of using DMET over clonidine has not yet been thoroughly assessed. Nevertheless, recent experimental studies seem to show that $\alpha 1$-AR activity counterbalances $\alpha 2$-AR-induced analgesia and, therefore, greater $\alpha 2$-AR selectivity may enhance the therapeutic window of $\alpha 2-A R$ in the treatment of pain [3]. Furthermore, DMET demonstrates a synergistic analgesic effect with clonidine at the spinal level by a mechanism involving their different affinities for the three $\alpha 2$-AR subtypes. Neither clonidine or DMET is totally selective for any one of the $\alpha 2$-AR subtypes but DMET (besides demonstrating a2A-AR binding properties) seems to have higher $\alpha 2 \mathrm{C}$-AR affinity than clonidine [4].

\section{Recent advances \\ Analgesic effects following systemic administration}

$\alpha 2$-AR agonists and opioids act by different mechanisms and thus their combination produces a synergistic analgesic effect without increasing the respiratory depression that is often associated with opioid use. Furthermore, the opioid-sparing effect is generally associated with a reduction in adverse effects such as nausea and vomiting. Therefore, $\alpha 2$-AR agonists have been found to be particularly useful in perioperative conditions. Recent studies, not surprisingly, show that intraoperative DMET (bolus dose of $0.5-1 \mu \mathrm{g} / \mathrm{kg}$, with or without continuous infusion of $0.5-2 \mu \mathrm{g} / \mathrm{kg}$ per hour) causes a significant reduction in the need for both intraoperative and postoperative analgesics in adults [5] and in children [6]. Even if the elimination half-life of DMET is short (i.e., 2-3 hours), the analgesic-sparing effect observed after a preoperative or an intraoperative administration usually lasts up to 24 hours, with the anxiolytic, sedative, and thymoanaleptic properties implicated as being partly responsible for this effect $[6,7]$. Self-administration of DMET by adding to intravenous patient-controlled analgesia morphine (5 $\mu \mathrm{g}$ DMET per $1 \mathrm{mg}$ morphine dose) improves postoperative analgesia and decreases postoperative morphine consumption by $30 \%$, as well as 
Table I. Major differences in the pharmacology of clonidine and dexmedetomidine

\begin{tabular}{|c|c|}
\hline Clonidine & Dexmedetomidine* \\
\hline Developed in the $1960 \mathrm{~s}$ & Developed in the 1980 s \\
\hline $\begin{array}{l}\text { Clinical practice: originally prescribed as a antihypertensive then as an } \\
\text { analgesic in chronic pain (1983) }\end{array}$ & $\begin{array}{l}\text { Clinical practice: tested in volunteers (199I) then used as a sedative in } \\
\text { ICU (I999) }\end{array}$ \\
\hline Ratio $\alpha 2: \alpha$ I receptor binding is $200: 1$ & Ratio $\alpha 2$ : $\alpha$ I receptor binding is $|600:|$ \\
\hline Octanol/buffer partition coefficient: 0.8 & $\begin{array}{l}\text { Octanol/buffer partition coefficient: } 2.8 \text { More lipophilic (3.5-fold) than } \\
\text { clonidine }\end{array}$ \\
\hline Plasmatic half-life $T 1 / 2: 9-12$ hours & Plasmatic half-life T1/2: $2-2.5$ hours \\
\hline Protein binding: $50 \%$ & Protein binding: $94 \%$ \\
\hline
\end{tabular}

decreasing morphine-induced side effects like nausea, without additional sedation [8].

Besides the analgesic effect of $\alpha 2-\mathrm{AR}$ agonists being independent of the opioid system, the block of sympathetic over-activity is another benefit of using these agents for some patients. For example, perioperative management in patients chronically taking opioids (i.e., opioid addicts and chronic pain patients) is a challenge because of their higher pain levels, opioid tolerance, and risk of opioid withdrawal. Although poorly explored, DMET may have special value in these patients by helping to control pain and to alleviate opioid withdrawal symptoms [9].

Even at high doses, $\alpha 2$-AR agonists combine analgesic, sedative, and anxiolytic properties with preservation of respiratory function. Although typically-used sedative drugs (e.g., propofol), short-acting opioids, ketamine, and midazolam may provide successful sedation, they can also induce harmful respiratory depression in highrisk patients and unsuitable paradoxical effects with agitation in elderly patients. DMET, like other $\alpha 2$-AR agonists, does not affect respiratory function. Moreover, DMET seems to possess neuroprotective effects and attenuates neurocognitive impairment (mainly delirium and agitation) following anesthesia [10]. In children undergoing tonsillectomy, the use of an intraoperative infusion of DMET reduced the frequence of severe emergence agitation in comparison with an intraoperative infusion of fentanyl. [11]. In the intensive care unit, the choice of DMET infusion for sedation and analgesia has a favourable effect on the prevalence and the duration of delirium and confusion associated with the use of midazolam or morphine $[12,13]$. Therefore, systemic $\alpha 2$-AR agonists may be used as a perioperative supplement to improve locoregional analgesia, and the pharmacokinetic profile of DMET makes its use easier than clonidine for that indication. Additionally, preand intraoperative DMET prolongs the duration of the sensory block of local anesthetics during spinal anesthesia [14] and peripheral nerve block [15]. It is worth noting that DMET premedication can be provided by different noninvasive routes, such as buccal and intranasal routes, with a very good bioavailability [16]. Postoperatively, intravenous DMET infusion as an adjunct to epidural analgesia allows for better pain control and reduces epidural analgesic consumption after major surgery [17].

Finally, besides the perioperative administration, it is interesting to mention the recent (although anecdotal) report of DMET use in obstetric analgesia. The report asserts that, because of its high lipophilicity, DMET is retained in placental tissue and passes less readily than clonidine into the fetal circulation and thereby is less susceptible to cause harmful fetal bradycardia. Continuous intravenous DMET infusion has been successfully used as an adjunct to unsatisfactory analgesia by systemic opioids in laboring parturients who could not benefit from epidural analgesia $[18,19]$. Like clonidine, DMET demonstrates an antinociceptive effect in visceral pain conditions [20]. Furthermore, the drug also possesses attractive properties such as maternal hemodynamic stability, anxiolysis, and stimulation of uterine contractions.

\section{Analgesic effects when used in locoregional analgesia}

Because the analgesic effect of $\alpha 2$-AR agonists is mostly mediated at spinal level, neuraxial administration is the route of choice for DMET. Moreover, its high lipophilicity allows for rapid absorption into the cerebrospinal fluid and binding to the spinal cord $\alpha 2$-AR.

A few clinical studies have examined the epidural administration of DMET (usual dose 1-2 $\mu \mathrm{g} / \mathrm{kg}$ ) in thoracic and upper abdominal surgery. Unsurprisingly, epidural DMET potentiates neuraxial local anesthetics, decreases intraoperative anesthetic requirements, and improves postoperative analgesia hence reducing pulmonary complications associated with thoracotomy [21]. However, according to studies performed to date, DMET does not seem to offer any significant advantage over clonidine in this respect; DMET produces a similar prolongation in the duration of the motor and sensory blocks induced by local anesthetics, regardless of the neuraxial route of 
administration (e.g., epidural [22], caudal [23], or spinal [24]). Incidence and magnitude of side effects like sedation and a decrease in systolic blood pressure (25$30 \%$ ) following sympathetic block also do not differ. The lack of advantage resulting from DMET neuraxial use over clonidine should be taken into account seeing as regular neurotoxicity screening has not been performed for DMET. Although the drug has neuroprotective effects, demyelination in the white matter was observed after epidural administration of DMET in rabbits [25]. Consequently, advanced pathologic investigations are required before using DMET by neuraxial route.

Clonidine is currently used as an analgesic adjuvant in peripheral nerve blocks. Direct inhibitory effects of $\alpha 2$-AR agonists on the conduction of $\mathrm{A} \delta$ and $\mathrm{C}$ sensory fibers inhibition of $\mathrm{I}_{\mathrm{h}}$ (hyperpolarization-activated) currents and (perhaps) inhibition of tetrodotoxin-resistant $\mathrm{Na}^{+}$channels - accounts for the potentiation of the intensity and duration of perineural local anesthetics. Experimental studies show a DMET dose-dependent increase in the duration of the sensory block induced by long-acting local anesthetics such as bupivacaine and ropivacaine $[26,27]$. A first prospective study in pediatric patients undergoing cleft palate repair and receiving greater palatine nerve block with bupivacaine also demonstrated a 50\% increase in the duration of postoperative analgesia [28]. Once again, although the experimental studies did not find neurotoxicity associated with perineural DMET injection, and have even found less perineural inflammation in the local anesthetic-DMET groups, caution remains before widespread clinical use [2]. Finally, peripheral analgesic effects of DMET that potentiate local anesthetics are mediated by a2A-AR binding [29]. Similar to the observations made with clonidine, addition of DMET to lidocaine for intravenous regional anesthesia improves the quality of intraoperative anesthesia and intra-articular administration of DMET decreases the need for postoperative analgesics after arthroscopic knee surgery [30].

\section{Implications for clinical practice}

Current perioperative applications for DMET rely on offlabel uses of the drug. Systemic administration (pre-, intra- and postoperative) is associated with a useful potentiation of both systemic analgesics, particularly opioids, and local anesthetic sensory block in neuraxial and perineural routes. Furthermore, at moderate doses (bolus dose of $<1 \mu \mathrm{g} / \mathrm{kg}$; continuous infusion $<2 \mu \mathrm{g} / \mathrm{kg}$ per hour), systemic DMET does not seem to induce unwanted hemodynamic side effects (e.g., hypotension and bradycardia). Consequently, systemic use as a supplement to general anesthesia and locoregional techniques seems the best and the safest indication for DMET use. However, neuraxial and perineural routes cannot be recommended before further neurotoxicity testing. In comparison with clonidine, currently, only the systemic route seems to show an advantage for DMET in accordance with the pharmacokinetic profile of the drug, while the neuraxial route does not seem to offer any advantage and the perineural route has not been assessed. Finally, potential applications for DMET outside of a perioperative context (i.e., in chronic pain therapy) certainly deserve further study.

\section{Abbreviations}

a2-AR, a2-adrenergic receptor; DMET, dexmedetomidine.

\section{Competing interests}

The authors declare that they have no competing interests.

\section{References}

I. Wagner DS, Brummett CM: Dexmedetomidine: as safe as safe can be. Semin Anesth Perioper Med Pain 2006, 25:77-83.

2. Gerner P: “Above all, do no harm”: hippocrates. Anesthesiology 2009, III:938-9.

3. Gil DW, Cheevers CV, Kedzie KM, Manlapaz CA, Rao S, Tang E, Donello JE: Alpha-I-adrenergic receptor agonist activity of clinical alpha-adrenergic receptor agonists interferes with alpha-2-mediated analgesia. Anesthesiology 2009, I I 0:40 I-7.

4. Fairbanks CA, Stone LS, Wilcox GL: Pharmacological profiles of alpha 2 adrenergic receptor agonists identified using genetically altered mice and isobolographic analysis. Pharmacol Ther 2009, I 23:224-38.

5. Massad IM, Mohsen WA, Basha AS, Al-Zaben KR, Al-Mustafa MM, Alghanem SM: A balanced anesthesia with dexmedetomidine decreases postoperative nausea and vomiting after laparoscopic surgery. Saudi Med J 2009, 30:|537-4I.

6. Al-Zaben KR, Qudaisat IY, Al-Ghanem SM, Massad IM, AlMustafa MM, Al-Oweidi AS, Abu-Halaweh SA, Abu-Ali HM, Saleem MM: Intraoperative administration of dexmedetomidine reduces the analgesic requirements for children undergoing hypospadius surgery. Eur J Anaesthesiol 2010, 27:247-52.

7. Unlugenc H, Gunduz M, Guler T, Yagmur O, Isik G: The effect of pre-anaesthetic administration of intravenous dexmedetomidine on postoperative pain in patients receiving patientcontrolled morphine. Eur J Anaesthesiol 2005, 22:386-91.

8. Lin TF, Yeh YC, Lin FS, Wang YP, Lin CJ, Sun WZ, Fan SZ: Effect of combining dexmedetomidine and morphine for intravenous patient-controlled analgesia. Br J Anaesth 2009, 102:I 17-22.

9. Brummett CM, Trivedi KA, Dubovoy AV, Berland DW: Dexmedetomidine as a novel therapeutic for postoperative pain in a patient treated with buprenorphine. J Opioid Manag 2009, 5:175-9.

10. Sanders RD, Xu J, Shu Y, Januszewski A, Halder S, Fidalgo A, Sun P, Hossain $M$, Ma D, Maze M: Dexmedetomidine attenuates isoflurane-induced neurocognitive impairment in neonatal rats. Anesthesiology 2009, I 1 0:1077-85.

FI000 Factor 6

Evaluated by Mike Crowder 05 May 2009

II. Patel A, Davidson M, Tran MC, Quraishi H, Schoenberg C, Sant M, Lin $A$, Sun $X$ : Dexmedetomidine infusion for analgesia and prevention of emergence agitation in children with obstructive sleep apnea syndrome undergoing tonsillectomy and adenoidectomy. Anesth Analg 2010, I II:1004-10.

12. Riker RR, Shehabi Y, Bokesch PM, Ceraso D, Wisemandle W, Koura F, Whitten P, Margolis BD, Byrne DW, Ely EW, Rocha MG; 
SEDCOM (Safety and Efficacy of Dexmedetomidine Compared With Midazolam) Study Group: Dexmedetomidine vs midazolam for sedation of critically ill patients: a randomized trial. JAMA 2009, 30 I:489-99.

\section{Changes Clinical Practice}

FI000 Factor 17

Evaluated by Anne-Cornelie de Pont 25 Feb 2009, Babak Sarani 09 Mar 2009, Keira Mason II Mar 2009, Alain Vuylsteke 24 Mar 2009, Matthias Eikermann 23 Apr 2009

13. Shehabi Y, Grant P, Wolfenden H, Hammond N, Bass F, Campbell M, Chen J: Prevalence of delirium with dexmedetomidine compared with morphine based therapy after cardiac surgery: a randomized controlled trial (DEXmedetomidine COmpared to Morphine-DEXCOM Study). Anesthesiology 2009, I I I: I075-84.

14. Kaya FN, Yavascaoglu B, Turker G, Yildirim A, Gurbet A, Mogol EB, Ozcan B: Intravenous dexmedetomidine, but not midazolam, prolongs bupivacaine spinal anesthesia. Can J Anaesth 2010, 57:39-45.

15. Rutkowska K, Knapik P, Misiolek H: The effect of dexmedetomidine sedation on brachial plexus block in patients with endstage renal disease. Eur J Anaesthesiol 2009, 26:85I-5.

FI000 Factor 6

Evaluated by Malachy Columb 26 Oct 2009

16. Yuen VM, Hui TW, Irwin MG, Yuen MK: A comparison of intranasal dexmedetomidine and oral midazolam for premedication in pediatric anesthesia: a double-blinded randomized controlled trial. Anesth Analg 2008, 106:1715-2I.

FI000 Factor 6

Evaluated by Keira Mason 21 Jan 2010

17. Akin S, Aribogan A, Arslan G: Dexmedetomidine as an adjunct to epidural analgesia after abdominal surgery in elderly intensive care patients: A prospective, double-blind, clinical trial. Curr Ther Res Clin Exp 2008, 69:16-28.

18. Abu-Halaweh SA, Al Oweidi AK, Abu-Malooh H, Zabalawi M, Alkazaleh F, Abu-Ali H, Ramsay MA: Intravenous dexmedetomidine infusion for labour analgesia in patient with preeclampsia. Eur J Anaesthesiol 2009, 26:86-7.

19. Palanisamy A, Klickovich RJ, Ramsay M, Ouyang DW, Tsen LC: Intravenous dexmedetomidine as an adjunct for labor analgesia and cesarean delivery anesthesia in a parturient with a tethered spinal cord. Int J Obstet Anesth 2009, 18:258-6I.

20. Ulger F, Bozkurt A, Bilge SS, Ilkaya F, Dilek A, Bostanci MO, Ciftcioglu $E$, Guldogus $F$ : The antinociceptive effects of intravenous dexmedetomidine in colorectal distension-induced visceral pain in rats: the role of opioid receptors. Anesth Analg 2009, 109:616-22.

21. Elhakim M, Abdelhamid D, Abdelfattach H, Magdy H, Elsayed A, Elshafei M: Effect of epidural dexmedetomidine on intraoperative awareness and post-operative pain after one-lung ventilation. Acta Anaesthesiol Scand 2010, 54:703-9.

22. Schnaider TB, Vieira AM, Brandao AC, Lobo MV: [Intraoperative analgesic effect of epidural ketamine, clonidine or dexmedetomidine for upper abdominal surgery]. Rev Bras Anestesiol 2005, 55:525-31.

23. El-Hennawy AM, Abd-Elwahab AM, Abd-Elmaksoud AM, ElOzairy HS, Boulis SR: Addition of clonidine or dexmedetomidine to bupivacaine prolongs caudal analgesia in children. $\mathrm{Br} J$ Anaesth 2009, 103:268-74.

24. Kanazi GE, Aouad MT, Jabbour-Khoury SI, Al Jazzar MD, Alameddine MM, Al-Yaman R, Bulbul M, Baraka AS: Effect of low-dose dexmedetomidine or clonidine on the characteristics of bupivacaine spinal block. Acta Anaesthesiol Scand 2006, 50:222-7.

25. Konakci S, Adanir T, Yilmaz G, Rezanko T: The efficacy and neurotoxicity of dexmedetomidine administered via the epidural route. Eur J Anaesthesiol 2008, 25:403-9.

26. Brummett CM, Norat MA, Palmisano JM, Lydic R: Perineural administration of dexmedetomidine in combination with bupivacaine enhances sensory and motor blockade in sciatic nerve block without inducing neurotoxicity in rat. Anesthesiology 2008, 109:502-II.

27. Brummett CM, Padda AK, Amodeo FS, Welch KB, Lydic R: Perineural dexmedetomidine added to ropivacaine causes a dose-dependent increase in the duration of thermal antinociception in sciatic nerve block in rat. Anesthesiology 2009, III:IIII-9.

28. Obayah GM, Refaie A, Aboushanab O, Ibraheem N, Abdelazees M: Addition of dexmedetomidine to bupivacaine for greater palatine nerve block prolongs postoperative analgesia after cleft palate repair. Eur J Anaesthesiol 2010, 27:280-4.

29. Yoshitomi T, Kohjitani A, Maeda S, Higuchi H, Shimada M, Miyawaki T: Dexmedetomidine enhances the local anesthetic action of lidocaine via an alpha-2A adrenoceptor. Anesth Analg 2008, 107:96-101.

30. Al-Metwalli RR, Mowafi HA, Ismail SA, Siddiqui AK, AI-Ghamdi AM, Shafi MA, El-Saleh AR: Effect of intra-articular dexmedetomidine on postoperative analgesia after arthroscopic knee surgery. Br J Anaesth 2008, I0I:395-9.

FI000 Factor 6

Evaluated by Pekka Talke 10 Jul 2008 